\title{
Assessing Utilisation and Expenditure on Long-Acting Insulin Analogues in Kenya; Findings and Implications for the Future
}

\author{
Sylvia Opanga ${ }^{1}$, Lisper Wangeci Njeri ${ }^{2}$, David Kimonge ${ }^{1}$, Brian Godman ${ }^{3-5^{*}}$, Margaret Oluka ${ }^{6}$
}

\author{
${ }^{1}$ Department of Pharmaceutics and Pharmacy Practice, School of Pharmacy, University of Nairobi, Nairobi, Kenya \\ ${ }^{2}$ Department of Pharmacy, Kenyatta National Hospital, Nairobi, Kenya \\ ${ }^{3}$ Strathclyde Institute of Pharmacy and Biomedical Sciences, University of Strathclyde, Glasgow G4 ORE, United Kingdom \\ ${ }^{4}$ Division of Public Health Pharmacy and Management, School of Pharmacy, Sefako Makgatho Health Sciences University, Pretoria, \\ South Africa \\ ${ }^{5}$ School of Pharmaceutical Sciences, Universiti Sains Malaysia, Penang, Malaysia \\ ${ }^{6}$ Department of Pharmacology and Pharmacognosy, School of Pharmacy, University of Nairobi, Nairobi, Kenya
}

DOI: $10.36347 /$ saip.2021.v10i04.002 $\quad$ | Received: 11.02.2021 | Accepted: 24.03.2021 | Published: 13.04 .2021

*Corresponding author: Brian Godman

Abstract

Prevalence rates for patients with diabetes mellitus are rising across countries including sub-Saharan African countries, which will continue. As a result, there are an increasing number of patients with insulin-dependent diabetes across subSaharan Africa including Kenya. Growing prevalence rates are increasing the costs of treating patients with diabetes enhanced by associated complications. These include both microvascular and macrovascular complications, with hypoglycaemia and generally poor control of diabetes contributing to the burden. Long-acting insulin analogues were developed to reduce rates of hypoglycaemia associated with insulin usage, including nocturnal hypoglycaemia, and improve adherence through improving patient convenience. As a result, they are now included in the Kenyan Essential Medicines List. However, long-acting insulin analogues are typically considerably more expensive than standard insulins limiting their use in practice, especially in countries such as Kenya with concerns with affordability even for standard insulins such as Mixtard®. Consequently, a need to ascertain current utilisation and expenditure patterns for the different insulins including long-acting insulin analogues across Kenya starting with leading referral hospitals. Research in Kenyatta National Hospital (KNH) showed growing use of insulin glargine reaching up to 3.4 to $3.6 \%$ of total insulin utilisation in 2019 and 2020 . However, prescribing was limited by considerably higher prices (3.4 fold higher) than standard insulins on a defined daily dose basis. Considerably higher prices resulted in no utilisation of long-acting insulin analogues in another leading referral hospital in Kenya. Overall, appreciably lowering the prices of long-acting insulin analogues through instigating local production and other activities should increase their use benefiting patients and the healthcare system in Kenya and wider. These are considerations for the future.

Keywords: Affordability, biosimilars, diabetes, drug utilisation, essential medicine lists, long-acting insulin analogues, Kenya, pharmaceutical health policy.

Copyright (C) 2021 The Author(s): This is an open-access article distributed under the terms of the Creative Commons Attribution 4.0 International License (CC BY-NC 4.0) which permits unrestricted use, distribution, and reproduction in any medium for non-commercial use provided the original author and source are credited.

\section{INTRODUCTION}

The prevalence of diabetes mellitus continues to rise across countries including sub-Saharan African countries enhanced by rising incidence rates [1-5], with the number of patients with diabetes in sub-Saharan Africa likely to reach 34.2 million by 2040, and potentially up to 42 to 47 million across Africa by 2045 [5-7]. These growing prevalence rates will have an appreciable impact on morbidity, including healthrelated quality of life, mortality and costs across subSaharan Africa and wider [2,8-12], building generally on the growing burden of non-communicable diseases
(NCDs) across sub-Saharan Africa [13,14]. We already see NCDs accounting for an appreciable number of inpatient beds in sub-Saharan Africa, and this will grow [15]. The actual burden of diabetes is also likely to be considerably higher in sub-Saharan Africa than current published rates given the appreciable number of undiagnosed patients [16]. This burden is enhanced by the associated micro- and macrovascular complications with diabetes, which include diabetic retinopathy, coronary vascular disease (CVD), chronic kidney disease (CKD), heart failure and ulceration including diabetic foot ulceration $[2,8,10,17-19]$, with 
hypoglycaemia and generally poor control of diabetes contributing to this burden [20-22].

Kenya is no exception with rising rates of NCDs, which will become the greatest disease burden by 2027 overtaking infectious diseases, and include patients with diabetes $[15,23]$. There are differences in prevalence rates between rural and urban populations in Kenya; however, current estimates are likely to be under-estimates given the considerable number of undiagnosed patients among the population [15].

Whilst the majority of patients with diabetes in sub-Saharan Africa, including Kenya, have type 2 diabetes (T2DM) as opposed to Type 1 diabetes (T1DM) [5, 24], an appreciable number of patients with diabetes are insulin dependent across low- and middleincome countries (LMICs) including sub-Saharan African countries [25-28]. This is a concern given the high costs of insulin and accompanying monitoring equipment among patients with diabetes mellitus in Kenya and wider with high co-payment levels outside of hospital, which can be catastrophic for some families [29]. Medicine costs are currently the greatest contributor to total direct costs among patients with diabetes in Kenya, accounting for an average $52.4 \%$ of total costs for those attending public healthcare facilities in Kenya [29]. Costs are enhanced by high levels of co-morbidities among patients with diabetes mellitus including hypertension, CVD and CKD, adding to the burden of the disease as well as access and affordability of medicines to treat diabetes and associated complications [5, 24, 30].

Access and availability of insulins generally is a continuing issue across low- and middle-income countries (LMICs) [31], highlighted in the studies by the ACCISS (Addressing the Challenge and Constraints of Insulin Sources and Supply) group [32-34]. There are similar concerns with the availability and costs of glucagon to treat any resultant hypoglycaemia among African countries [35].

High costs of insulin have been exacerbated by the lack of competition with three principal manufacturers globally accounting for up to $96 \%$ of the global market by volume and up to $99 \%$ by value [32, $34,36,37]$. Having said this, we are seeing a range of initiatives among sub-Saharan African countries to enhance diagnosis and affordability of insulins, and this is likely to continue. Initiatives include the Changing Diabetes in Children' (cCDiC) initiative launched in 2010 in Cameroon to offer free diabetes care to children and adolescents with T1DM as access and availability to insulins, as well as blood glucose monitoring equipment, had been a major issue [38-40]. There are similar initiatives in Nigeria with Novo Nordisk looking to offer insulin free to children during 2021 [41]. The International Insulin Foundation has also worked with governments in Mozambique and Zambia to enhance access to insulin [42], and in Tanzania, Biocon is looking to take part in a pan-African project entitled 'Mission 10 cents' whereby insulins, including recombinant human insulin (rh-insulin), will be sold at a cost of less than 10 US cents per day [43].

There have also been a number of initiatives in Kenya to enhance the affordability of medicines to treat patients with NCDs $[30,44]$. This includes the Base of Pyramid (BoP) project, which aimed to enhance the diagnosis of patients with diabetes as well as establish a ceiling price of KSh 500-600 (US\$5) for insulin Mixtard $®$ among participating healthcare facilities as well as surrounding markets and private pharmacies [45]. This should enhance affordability of medicines including insulins for patients with diabetes as this equates up to a two-thirds price reduction [45].

With respect to insulins, we have seen the development of long-acting insulin analogues to reduce rates of hypoglycaemia, especially nocturnal hypoglycaemia, and improve adherence through improved patient comfort [2,46-53]. This is welcomed given, as mentioned, concerns with the availability and costs of glucagon to treat hypoglycaemia when this occurs among African countries [35]. However, other authors are less certain of the patient benefits of longacting insulin analogues versus standard insulins such as Neutral Protamine Hagedorn (NPH) insulin, which combined with appreciably higher costs, has resulted in concerns with their availability and funding within healthcare systems especially in LMICs [31,54-57]. Despite these concerns, there has been continued growth in the utilisation of long-acting insulin analogues in high and high-middle income countries, and they are now the most prescribed insulin in these countries [31, 58]. There has also been continued growth in their use in Bangladesh with perceived benefits on patient care outweighing additional costs [59]. This has been helped by increasing use of biosimilars at lower costs [59].

Whilst long-acting insulin analogues are listed in the Kenyan Essential Medicine List (KEML) [60], there is likely to be limited use and funding in view of considerable price differences with NPH and other insulins along with affordability concerns [30, 45, 61]. Biosimilars offer a way forward to increase competition and potentially lower prices of long-acting insulin analogues as seen in Bangladesh [59]. However, this has not been the case to date among a number of LMICs where biosimilar insulin glargine can be more expensive than the originator [31]. There have also been more limited price reductions for biosimilar insulin glargine among some European countries, impacting on their use in practice $[62,63]$. However, this may change with the introduction of the World Health Organisation (WHO) prequalification initiative [64]. In addition, we 
Sylvia Opanga et al., Sch Acad J Pharm, Apr, 2021; 10(4): 63-70

are aware of initiatives across Africa to stimulate local production of medicines to lower their costs and reduce shortages following challenges seen with the recent COVID-19 pandemic [65-67], especially given the potential low costs of goods for biosimilar insulin glargine [68].

Consequently, given current challenges and controversy, we wanted to investigate current insulin utilisation and expenditure patterns in Kenya. In addition, ascertain potential measures that could be undertaken if pertinent in Kenya to enhance future availability and funding for long-acting insulin analogues including biosimilars to benefit patients.

\section{METHODOLOGY}

We assessed current utilisation and expenditure patterns for insulins among two major hospitals in Kenya. These included Kenyatta National Hospital (KNH) and Embu County Referral Hospital (ECRH). KNH is a 2000 bed national teaching and the largest public referral hospital in the region, offering quality specialized healthcare to patients across Kenya and wider $[69,70]$. ECRH is a level 5 regional teaching referral hospital located in Embu County offering high quality health care delivery and training of healthcare professionals [71]. Embu is located in Central Kenya, a region with high prevalence of diabetes mellitus. Consequently, both hospitals can provide good insight into the current situation in Kenya with respect to long- acting insulin analogues starting with key referral hospitals.

Current utilisation patterns were broken down into the various insulin types including rapid acting, standard, longer-acting and long-acting insulin analogues, as well as mixed preparations [72]. Utilisation was documented in vials and packs as well as defined daily doses (DDDs) in order to track specific patterns over time. We have used this approach in an earlier paper documenting medicine utilisation patterns in $\mathrm{KNH}$ as well as utilisation and cost patterns in Bangladesh and generally across countries [59, 70, 73, 74]. Expenditure patterns were kept in local currency (Ksh) without conversion to US dollars as we wanted to track changes over time without worrying about currency conversions. We have used this approach before $[75,76]$.

\section{RESULTS}

We have seen variable utilisation and expenditure on insulins over time in $\mathrm{KNH}$ (Table 1) depending on current affordability and other issues, with patients subsequently purchasing their insulins from community pharmacies when stocks run out.

Utilisation patterns reflect those listed in the Kenyan EML, which includes ultra short acting insulin (Rapid); short acting insulins (soluble), intermediate acting insulins, premixed insulins and insulin glargine [60].

Table-1: Utilisation and expenditure on insulins in KNH 2015 to 2020

\begin{tabular}{|c|c|c|c|c|c|c|c|c|c|c|c|c|}
\hline \multirow[b]{2}{*}{ Insulin Name } & \multicolumn{2}{|c|}{2015} & \multicolumn{2}{|c|}{2016} & \multicolumn{2}{|c|}{2017} & \multicolumn{2}{|c|}{2018} & \multicolumn{2}{|c|}{2019} & \multicolumn{2}{|c|}{2020 (Jan to Oct) } \\
\hline & DDDs & Exp & DDDs & Exp & DDD & Exp & DDD & Exp & DDD & Exp & DDD & Exp \\
\hline \multicolumn{13}{|l|}{ Rapid Acting } \\
\hline Rapid acting insulin (Aspart ${ }^{\oplus}$ or Lispro ${ }^{\oplus}$ ) Vial & 950 & 85500 & 725 & 65250 & 1200 & 108000 & 2775 & 249750 & 1250 & 112500 & 300 & 27000 \\
\hline Rapid acting insulin (Aspart ${ }^{\oplus}$ or Lispro ${ }^{\oplus}$ ) Flexpen - 3ml & 0 & 0 & 0 & 0 & 0 & 0 & 0 & 0 & 7.5 & 1450 & 0 & 0 \\
\hline \multicolumn{13}{|l|}{ Standard insulins including intermediate and premixed insulins } \\
\hline Insulin soluble cartridge & 0 & & 0 & 0 & 375 & 30600 & 75 & 6120 & 300 & 24480 & 37.5 & 3060 \\
\hline Soluble insulin vial & 15800 & 227520 & 19025 & 273960 & 16300 & 234720 & 25400 & 365760 & 31625 & 455400 & 24350 & 350640 \\
\hline Intermediate acting insulin(Humalog ${ }^{\oplus}$ mix $\left.75 \% / 25 \%\right)$ cartridge & 7582.5 & 1041330 & 7275 & 999100 & 5460 & 749840 & 5940 & 815760 & 5835 & 801340 & 1642.5 & 225570 \\
\hline Intermediate acting insulin(Humalog mix 75\%/25\%)vial & 0 & 0 & 0 & 0 & 2550 & 255000 & 10925 & 1092500 & 4700 & 470000 & 1950 & 195000 \\
\hline Intermediate acting insulin NPH vial & 0 & 0 & 0 & 0 & 2675 & 47080 & 2550 & 44880 & 1950 & 34320 & 1825 & 32120 \\
\hline Human insulin isophane suspension (Humulin ${ }^{\circledR} \mathrm{N}$ ) & 450 & & 0 & & 75 & & 37.5 & & 0 & & 37.5 & \\
\hline Insulin Isophane 70\% + Regular 30\% Penfill single vial & 0 & 0 & 0 & 0 & 50 & 7900 & 25 & 3950 & 0 & 0 & 0 & 0 \\
\hline Insulin Isophane 70\% + Regular 30\% vial (Mixtard ${ }^{\circledR}$ ) & 559825 & 7834050 & 306525 & 4291350 & 206400 & 2889600 & 212175 & 2970450 & 248125 & 3473750 & 205625 & 2878750 \\
\hline Premixed insulin 50\%/50\% vial & 4125 & 181500 & 7250 & 319000 & 6750 & 297000 & 2625 & 115500 & 1850 & 81400 & 125 & 5500 \\
\hline \multicolumn{13}{|l|}{ Long-acting insulin analogues } \\
\hline Long acting basal insulin (Lantus ${ }^{\oplus}$ ) vial & 0 & 0 & 0 & 0 & 975 & 46800 & 5800 & 278400 & 8000 & 384000 & 6775 & 325200 \\
\hline Basal analogue insulin glargine or equivalent (Lantus ${ }^{\oplus}$ ) cartridge & 3015 & & 1260 & & 2227.5 & & 2880 & & 3075 & & 1470 & \\
\hline Total DDDs & 591747.5 & & 342060 & & 245038 & & 271208 & & 306718 & & 244138 & \\
\hline$\%$ long-acting insulin analogues (DDD) & 0.51 & 0.00 & 0.37 & 0.00 & 1.31 & 1.00 & 3.20 & 4.68 & 3.61 & 6.58 & 3.38 & 8.04 \\
\hline \multicolumn{13}{|l|}{ Cost/ DDD } \\
\hline Cost/DDD long acting basal insulin (Lantus $\left.{ }^{\circledR}\right)$ vial & & & & & & 48.00 & & 48.00 & & 48.00 & & 48.00 \\
\hline Cost/ DDD soluble insulin vial & & 14.40 & & 14.40 & & 14.40 & & 14.40 & & 14.40 & & 14.40 \\
\hline Cost/ DDD Mixtard & & 13.99 & & 14.00 & & 14.00 & & 14.00 & & 14.00 & & 14.00 \\
\hline
\end{tabular}

NB: Utilisation is in DDDs and expenditure in Ksh

The low use of insulin glargine, up to a maximum of 3.2 to $3.6 \%$ of total insulins in recent years, reflects issues of affordability especially given appreciable differences in procured costs (cost/ DDD) between soluble insulin and insulin Mixtard® versus those for insulin glargine (Table 1). The higher cost of insulin glargine (cost/ DDD) is reflected in a greater 
contribution of insulin glargine to total expenditure than for total utilisation rising up to $8.0 \%$ in 2020 (Table 1).

Overall, it is likely there will be limited or no use of long-acting insulin analogues, including potential biosimilars, in public hospitals outside of $\mathrm{KNH}$ with patients in Kenya struggling to fund even insulin Mixtard® without specific access schemes [44, 45]. This was seen in ECRH where Mixtard ${ }^{\circledR}$ was the principal insulin dispensed with usage rising from 2061 packs in $2015(511,360 \mathrm{Ksh})$ to 5627 packs in 2018 $(1,800,640 \mathrm{Ksh})$ before falling to 4742 packs in 2019 , with similar utilisation and expenditure patterns up to June 2020. There was no dispensing of any long-acting insulin analogue in this referral hospital in recent years.

\section{DISCUSSION}

We believe this is the first study in Kenya to track the use of long-acting insulin analogues within the public healthcare system starting with leading referral hospitals. Overall, as envisaged, there is limited use of long-acting insulin analogues due primarily with issues of affordability given appreciably higher costs (Table 1) within these referral hospitals. This is different to Bangladesh where we have seen increasing use of longacting insulin analogues in recent years [59]. The current price gap between the different insulins (Table 1) is likely to be greater among community pharmacies once dispensing and other costs are added in [77], further exacerbating issues of affordability for the general population unless actively addressed.

The principal goal in sub-Saharan African countries such as Kenya is to make sure appropriate healthcare facilities, personnel, and medicines are in place to manage patients with diabetes. This includes preventing patients with T2DM from becoming insulin dependent, as well as making sure once insulin is needed that there is access and availability to insulins such as NPH insulins and insulin Mixtard ${ }^{\circledR}$ as well as blood glucose monitoring equipment given current concerns [8, 24, 45, 61]. Following this, it is important that patients have a full range of insulins available to them to improve their care, building on those available in higher income countries $[2,31]$. This is facilitated in Kenya by long-acting insulin analogues already listed in the Kenyan EML [60]. Compliance is a critical issue with treatments for patients with diabetes including insulins, with pharmacists also playing a role to improve the control of diabetes and its complications [78-80].

However, it is likely that prices of long-acting insulin analogues would need to fall to close to those for NPH insulins and insulin Mixtard ${ }^{\circledR}$ to enhance funding and usage, similar to ongoing regulations in LMICs such as Brazil and South Africa [81,82]. This could be achieved through potentially instigating local production of biosimilar insulin glargine, similar to initiatives in Malaysia through Biocon or other companies [83]. This also builds on suggestions by the East African Secretariat to enhance production of medicines in Africa to reduce future shortages as a result of pandemics and other circumstances [65, 66]. This could be in addition to the WHO prequalification initiative to enhance competition among insulin manufacturers to lower the price of biosimilars and break the near monopoly of the three main insulin manufacturers [34, 36, 37, 64]. Potentially similar, or slightly higher, cost of goods for insulin glargine versus NPH insulins should help here [68].

Once underway, key physician and pharmacy groups can educate all key stakeholders regarding similar safety and effectiveness between originator and biosimilar long-acting insulin analogues if this is perceived to be a problem to avoid/ reduce any negative nocebo effects [84-87]. This can be facilitated by pharmaceutical manufacturers and others instigating studies in sub-Saharan Africa to compare the effectiveness and value of biosimilar insulin glargine versus NPH and other insulins given the lack of such studies currently in sub-Saharan Africa. Physicians, pharmacists, and nurse practitioners can subsequently work with patients to ensure they are familiar with any difference in pens/ devices between the different insulin glargine preparations if this proves to be a concern. In addition, provide educational and other support to enhance adherence to regular administration of longacting insulin analogues in patients' home to reduce any potential hypoglycaemia. Subsequently, routinely monitor patients and medicine use during follow-up visits to ambulatory care clinics in hospitals and primary healthcare centres to address key issues including HbA1c levels, hypertension and statin administration given ongoing concerns across subSaharan Africa [88].

We are aware of a number of limitations with this study. The principal ones are that the research was only undertaken in two leading hospitals in Kenya. However, this was deliberate since if there was limited use of long-acting insulin analogues in these facilities, these patterns would be seen throughout Kenya. We also did not explore rates of hypoglycaemia and other complications among diabetes patients attending clinics in these facilities. However, this was outside the scope of this paper. Similarly, we did not monitor current utilisation patterns within private hospitals in Kenya as our emphasis was on the public system where the vast majority of patients are treated. Despite these issues, we believe this paper provides a valuable insight into current insulin use among leading hospitals in Kenya.

In conclusion, there is currently limited use of long-acting insulin analogues in Kenya due primarily to issues of affordability. Biosimilars can potentially help. However, their prices need to be nearer to those for 
Sylvia Opanga et al., Sch Acad J Pharm, Apr, 2021; 10(4): 63-70

NPH and other similar insulins to enhance future use and funding despite listing in the Kenyan EML. These are considerations for the future enhanced by ongoing WHO prequalification and other initiatives.

\section{Conflicts of interest and funding}

The authors declare they have no competing interests. This analysis was commissioned and paid for by the World Health Organization. The authors are totally responsible for the views expressed in this paper and they do not necessarily represent the decisions, policy or views of the World Health Organization.

\section{REFERENCES}

1. Tuomilehto J, Ogle GD, Lund-Blix NA, Stene LC. Update on Worldwide Trends in Occurrence of Childhood Type 1 Diabetes in 2020. Pediatric endocrinology reviews: PER. 2020 Mar 1;17(Suppl 1):198-209.

2. Chan JC, Lim LL, Wareham NJ, Shaw JE, Orchard TJ, Zhang P, Lau ES, Eliasson B, Kong AP, Ezzati M, Aguilar-Salinas CA. The Lancet Commission on diabetes: using data to transform diabetes care and patient lives. The Lancet. 2020 Dec 19;396(10267):2019-82.

3. Liu J, Ren ZH, Qiang H, Wu J, Shen M, Zhang L, Lyu J. Trends in the incidence of diabetes mellitus: results from the Global Burden of Disease Study 2017 and implications for diabetes mellitus prevention. BMC public health. 2020 Dec;20(1):1-2.

4. Kibirige D, Lumu W, Jones AG, Smeeth L, Hattersley AT, Nyirenda MJ. Understanding the manifestation of diabetes in sub Saharan Africa to inform therapeutic approaches and preventive strategies: a narrative review. Clinical diabetes and endocrinology. 2019 Dec;5(1):1-8.

5. Godman B, Basu D, Pillay Y, Mwita JC, Rwegerera GM, Paramadhas BD, Tiroyakgosi C, Okwen PM, Niba LL, Nonvignon J, Sefah I. Review of ongoing activities and challenges to improve the care of patients with type 2 diabetes across Africa and the implications for the future. Frontiers in pharmacology. 2020;11.

6. International Diabetes Feceration. IDF Africa Members. 2019. Available at URL: https://idf.org/ournetwork/regions-members/africa/members/25-southafrica.html.

7. Hamid S, Groot W, Pavlova M. Trends in cardiovascular diseases and associated risks in subSaharan Africa: a review of the evidence for Ghana, Nigeria, South Africa, Sudan and Tanzania. The aging male. 2019 Jul 3;22(3):169-76.

8. Atun R, Davies JI, Gale EA, Bärnighausen T, Beran D, Kengne AP, Levitt NS, Mangugu FW, Nyirenda MJ, Ogle GD, Ramaiya K. Diabetes in sub-Saharan Africa: from clinical care to health policy. The lancet Diabetes \& endocrinology. 2017 Aug 1;5(8):622-67.

9. Bommer C, Sagalova V, Heesemann E, ManneGoehler J, Atun R, Bärnighausen T, Davies J, Vollmer S. Global economic burden of diabetes in adults: projections from 2015 to 2030. Diabetes care. 2018 May 1;41(5):963-70.

10. Mapa-Tassou C, Katte JC, Maadjhou CM, Mbanya JC. Economic impact of diabetes in Africa. Current diabetes reports. 2019 Feb 1;19(2):5.

11. Mutyambizi C, Pavlova M, Chola L, Hongoro C, Groot W. Cost of diabetes mellitus in Africa: a systematic review of existing literature. Globalization and health. 2018 Dec;14(1):1-3.

12. Tusa BS, Weldesenbet AB, Gemada AT, Merga BT, Regassa LD. Heath related quality of life and associated factors among diabetes patients in subSaharan countries: a systemic review and metaanalysis. Health and Quality of Life Outcomes. 2021 Dec;19(1):1-3.

13. Bigna JJ, Noubiap JJ. The rising burden of noncommunicable diseases in sub-Saharan Africa. The Lancet Global Health. 2019 Oct 1;7(10):e1295-6.

14. Gouda HN, Charlson F, Sorsdahl K, Ahmadzada S, Ferrari AJ, Erskine H, Leung J, Santamauro D, Lund C, Aminde LN, Mayosi BM. Burden of noncommunicable diseases in sub-Saharan Africa, 1990 2017: results from the Global Burden of Disease Study 2017. The Lancet Global Health. 2019 Oct 1;7(10):e1375-87.

15. Shiroya V, Neuhann F, Müller O, Deckert A. Challenges in policy reforms for non-communicable diseases: the case of diabetes in Kenya. Global health action. 2019 Jan 1;12(1):1611243.

16. Asmelash D, Asmelash Y. The burden of undiagnosed diabetes mellitus in adult African population: a systematic review and meta-analysis. Journal of diabetes research. 2019 Apr 28;2019.

17. Rwegerera GM, Molefe-Baikai OJ, Masaka A, Shimwela M, Rivera YP, Oyewo TA, Godman BB, Massele A, Habte D. Prevalence of chronic kidney disease using estimated glomerular filtration rate among diabetes patients attending a tertiary clinic in Botswana. Hospital practice. 2018 Aug 8;46(4):21420.

18. He J, Shlipak M, Anderson A, Roy JA, Feldman HI, Kallem RR, Kanthety R, Kusek JW, Ojo A, Rahman M, Ricardo AC. Risk factors for heart failure in patients with chronic kidney disease: the CRIC (Chronic Renal Insufficiency Cohort) study. Journal of the American Heart Association. 2017 May 17;6(5):e005336.

19. International Diabetes Federation. IDF Atlas Ninth Edition (full). 2019. Available at URL: https://diabetesatlas.org/upload/resources/material/202 00302_133351_IDFATLAS9e-final-web.pdf.

20. Hypoglycaemia, cardiovascular disease, and mortality in diabetes: epidemiology, pathogenesis, and management. The lancet Diabetes \& endocrinology. 2019;7(5):385-96.

21. Mbanya JC, Naidoo P, Kolawole BA, Tsymbal E, McMaster A, Karamchand S. Management of adult patients with type 1 diabetes mellitus in Africa: A post-hoc cohort analysis of 12 African countries participating in the International Diabetes Management Practices Study (Wave 7). Medicine. 2020;99(25):e20553. 
22. Pillay DK, Ross AJ, Campbell L. A review of hypoglycaemia in a South African family practice setting. African journal of primary health care \& family medicine. 2016;8(1):e1-e6.

23. Republic of Kenya Ministry of Health. Kenya National Strategy for the Prevention and Control of Non-Communicable Diseases 2015-2022. 2015. Available at URL: https://www.who.int/nmh/ncdtask-force/kenya-strategy-ncds-2015-2020.pdf

24. Godman B, Basu D, Pillay Y, Almeida P, Mwita JC, Rwegerera GM. Ongoing and planned activities to improve the management of patients with Type 1 diabetes across Africa; implications for the future. Hospital practice. 2020;48(2):51-67.

25. Mohan V, Shah SN, Joshi SR, Seshiah V, Sahay BK, Banerjee S. Current status of management, control, complications and psychosocial aspects of patients with diabetes in India: Results from the DiabCare India 2011 Study. Indian J Endocrinol Metab. 2014;18(3):370-8.

26. Venkataraman AP, Laxminarayana K, Samhita S. Knowledge, Attitude and Practice of Insulin Use of Diabetic Patients in India. Pharmacology and Clinical Pharmacy Research. 2020; 5 (1): 23-32.

27. Elliot J, Besançon S, Sachs J. Almost 100 years after it was discovered, let's make access to insulin a reality in Africa! 2016. Available at URL: https://ideas4development.org/en/almost-100-yearsafter-it-was-discovered-lets-make-access-to-insulin-areality-in-africa/.

28. Claude Mbanya J, Aschner P, Chan JCN, Jose Gagliardino J, Saji J. Self-monitoring of blood glucose (SMBG) and glycaemic control in Cameroon: Results of the International Diabetes Management Practices Study (IDMPS). Diabetes research and clinical practice. 2017;126:198-201.

29. Oyando R, Njoroge M, Nguhiu P, Sigilai A, Kirui F, Mbui J. Patient costs of diabetes mellitus care in public health care facilities in Kenya. The International journal of health planning and management. 2020;35(1):290-308.

30. Mbui JM, Oluka MN, Guantai EM, Sinei KA, Achieng L, Baker A. Prescription patterns and adequacy of blood pressure control among adult hypertensive patients in Kenya; findings and implications. Expert review of clinical pharmacology. 2017;10(11):1263-71.

31. Ewen M, Joosse HJ, Beran D, Laing R. Insulin prices, availability and affordability in 13 low-income and middle-income countries. BMJ global health. 2019;4(3):e001410.

32. Beran D, Ewen M, Lepeska M, Laing R. Access to insulin: current challenges and constraints. Health Action International. 2017. Available at URL: https://haiweb.org/wpcontent/uploads/2017/03/Issues_Paper_2017.pdf.

33. Beran D, Hirsch IB, Yudkin JS. Why Are We Failing to Address the Issue of Access to Insulin? A National and Global Perspective. Diabetes Care. 2018;41(6):1125-31.

34. Beran D, Laing RO, Kaplan W, Knox R, Sharma A, Wirtz VJ. A perspective on global access to insulin: a descriptive study of the market, trade flows and prices. Diabetic medicine. 2019;36(6):726-33.

35. Rowlands A, Ameyaw E, Rutagarama F, Dipesalema J, Majaliwa ES, Mbogo J. Insights from the WHO and National Lists of Essential Medicines: Focus on Pediatric Diabetes Care in Africa. Hormone research in paediatrics. 2018;90(2):82-92.

36. WHO. Changing the game to improve availability and affordability of quality-assured insulin and associated devices. 2020. Available at URL: https://www.who.int/news/item/25-09-2020changing-the-game-to-improve-availability-andaffordability-of-quality-assured-insulin-andassociated-devices.

37. Beran D, Lazo-Porras M, Mba CM, Mbanya JC. A global perspective on the issue of access to insulin. Diabetologia. 2021

38. Lontchi-Yimagou E, Mapa-Tassou C, Dehayem MY, Essi MJ, Saji J, Takogue R. The effect of free diabetes care on metabolic control and on health-related quality of life among youths with type 1 diabetes in Cameroon. BMJ open diabetes research \& care. 2017;5(1):e000397.

39. Dehayem MY, Takogue R, Choukem SP, Donfack OT, Katte JC, Sap S. Impact of a pioneer diabetes camp experience on glycemic control among children and adolescents living with type 1 diabetes in subSaharan Africa. BMC Endocr Disord. 2016;16:5.

40. Schäfermann S, Neci R, Ndze EN, Nyaah F, Pondo VB, Heide L. Availability, prices and affordability of selected antibiotics and medicines against noncommunicable diseases in western Cameroon and northeast DR Congo. PloS one. 2020;15(1):e0227515.

41. Premium Times. Diabetes: Novo Nordisk to offer free insulin to children in Nigeria, Ghana. 2020. Available at URL:

https://www.premiumtimesng.com/health/426147diabetes-novo-nordisk-to-offer-free-insulin-tochildren-in-nigeria-ghana.html.

42. International Insulin Foundation - Fact Sheet on diabetes in sub-Saharan Africa. Available at URL: http://www.access2insulin.org/uploads/4/9/1/0/49101 07/factsheet.pdf.

43. Ndilwa L. Reason to smile for diabetic patients in Tanzania. December 2020. Available at URL: https://www.thecitizen.co.tz/tanzania/news/reason-tosmile-for-diabetic-patients-in-tanzania-3230790.

44. Sandoz - A Novartis Division. Kenya is first country to launch 'Novartis Access', expanding affordable treatment options against chronic diseases. 2015. Available at URL: https://www.sandoz.com/news/media-releases/kenyafirst-country-launch-novartis-access-expandingaffordable-treatment.

45. Shannon GD, Haghparast-Bidgoli H, Chelagat W, Kibachio J, Skordis-Worrall J. Innovating to increase access to diabetes care in Kenya: an evaluation of Novo Nordisk's base of the pyramid project. Glob Health Action. 2019;12(1):1605704.

46. Laranjeira FO, de Andrade KRC, Figueiredo A, Silva EN, Pereira MG. Long-acting insulin analogues for type 1 diabetes: An overview of systematic reviews 
and meta-analysis of randomized controlled trials. PloS one. 2018;13(4):e0194801.

47. Rys P, Wojciechowski P, Rogoz-Sitek A, Niesyczyński G, Lis J, Syta A. Systematic review and meta-analysis of randomized clinical trials comparing efficacy and safety outcomes of insulin glargine with NPH insulin, premixed insulin preparations or with insulin detemir in type 2 diabetes mellitus. Acta diabetologica. 2015;52(4):649-62.

48. Pedersen-Bjergaard U, Kristensen PL, Beck-Nielsen H, Nørgaard K, Perrild H, Christiansen JS. Effect of insulin analogues on risk of severe hypoglycaemia in patients with type 1 diabetes prone to recurrent severe hypoglycaemia (HypoAna trial): a prospective, randomised, open-label, blinded-endpoint crossover trial. The lancet Diabetes \& endocrinology. 2014;2(7):553-61.

49. Monami M, Marchionni N, Mannucci E. Long-acting insulin analogues vs. NPH human insulin in type 1 diabetes. A meta-analysis. Diabetes, obesity \& metabolism. 2009;11(4):372-8.

50. Gururaj Setty S, Crasto W, Jarvis J, Khunti K, Davies MJ. New insulins and newer insulin regimens: a review of their role in improving glycaemic control in patients with diabetes. Postgrad Med J. 2016;92(1085):152-64.

51. Berard L, Cameron B, Woo V, Stewart J. Replacing Insulin Glargine with Neutral Protamine Hagedorn (NPH) Insulin in a Subpopulation of Study Subjects in the Action to Control Cardiovascular Risk in Diabetes (ACCORD): Effects on Blood Glucose Levels, Hypoglycemia and Patient Satisfaction. Canadian journal of diabetes. 2015;39(4):296-301.

52. Alemayehu B, Speiser J, Bloudek L, Sarnes E. Costs associated with long-acting insulin analogues in patients with diabetes. The American journal of managed care. 2018; 24(8 Spec No.):Sp265-sp72.

53. Tricco AC, Ashoor HM, Antony J, Bouck Z, Rodrigues M, Pham B. Comparative Efficacy and Safety of Ultra-Long-Acting, Long-Acting, Intermediate-Acting, and Biosimilar Insulins for Type 1 Diabetes Mellitus: a Systematic Review and Network Meta-Analysis. J Gen Intern Med. 2021.

54. Caires de Souza AL, de Assis Acurcio F, Guerra Junior AA, Rezende Macedo do Nascimento RC, Godman B, Diniz LM. Insulin glargine in a Brazilian state: should the government disinvest? An assessment based on a systematic review. Applied health economics and health policy. 2014;12(1):1932.

55. Almeida P, Silva TBC, de Assis Acurcio F, Guerra Junior AA, Araujo VE, Diniz LM. Quality of Life of Patients with Type 1 Diabetes Mellitus Using Insulin Analog Glargine Compared with NPH Insulin: A Systematic Review and Policy Implications. The patient. 2018;11(4):377-89.

56. Marra LP, Araujo VE, Silva TB, Diniz LM, Guerra Junior AA, Acurcio FA. Clinical Effectiveness and Safety of Analog Glargine in Type 1 Diabetes: A Systematic Review and Meta-Analysis. Diabetes therapy. 2016;7(2):241-58.
57. Hemmingsen B, Metzendorf MI, Richter B. (Ultra)long-acting insulin analogues for people with type 1 diabetes mellitus. The Cochrane database of systematic reviews. 2021;3:Cd013498.

58. Cefalu WT, Dawes DE, Gavlak G, Goldman D, Herman WH, Van Nuys K. Insulin Access and Affordability Working Group: Conclusions and Recommendations. Diabetes Care. 2018;41(6):1299311.

59. Haque M, Islam S, Kamal ZM, Akter F, Jahan I, Rahim MSA. Ongoing efforts to improve the management of patients with diabetes in Bangladesh and the implications. Hospital practice. 2021.

60. Ministry of Health Republic of Kenya. Kenya Essential medicines list - 2019. Availabe at URL: https://www.health.go.ke/wpcontent/uploads/2020/03/Kenya-Essential-MedicinesList-2019.pdf.

61. Wirtz VJ, Turpin K, Laing RO, Mukiira CK, Rockers PC. Access to medicines for asthma, diabetes and hypertension in eight counties of Kenya. Trop Med Int Health. 2018;23(8):879-85.

62. Greener M. Why isn't the NHS making the most of biosimilar insulin? Prescriber August 2019: 21-24.

63. Greater Glasgow and Clyde. Medicines Update Semglee ${ }^{\circledR}$ - preferred brand of insulin glargine. 2020. Available at URL: http://ggcprescribing.org.uk/blog/alternatives-insulinglargine-post-tc/.

64. WHO. WHO launches first-ever insulin prequalification programme to expand access to lifesaving treatment for diabetes. 2019. Available at URL: https://www.who.int/news/item/13-11-2019who-launches-first-ever-insulin-prequalificationprogramme-to-expand-access-to-life-savingtreatment-for-diabetes.

65. EAC Secretariat. East African Community COVID-19 Response Plan. 2020. Available at URL: https://www.eac.int/coronavirus.

66. Ogunleye OO, Basu D, Mueller D, Sneddon J, Seaton RA, Yinka-Ogunleye AF. Response to the Novel Corona Virus (COVID-19) Pandemic Across Africa: Successes, Challenges, and Implications for the Future. Frontiers in pharmacology. 2020;11(1205).

67. Ekeigwe AA. Drug manufacturing and access to medicines: the West African story. A literature review of challenges and proposed remediation. AAPS Open. 2019; 5:3. doi.org/10.1186/s41120-019-0032-x.

68. Gotham D, Barber MJ, Hill A. Production costs and potential prices for biosimilars of human insulin and insulin analogues. BMJ global health. 2018;3(5):e000850.

69. Kenyatta National Hospital. STRATEGIC PLAN 2013-2018. Available at URL: http://knh.or.ke/wpcontent/uploads/2017/03/KNH_Strategic_Plan_20132018.pdf.pdf.

70. Kivoto PM, Mulaku M, Ouma C, Ferrario A, Kurdi A, Godman B. Clinical and Financial Implications of Medicine Consumption Patterns at a Leading Referral Hospital in Kenya to Guide Future Planning of Care. Frontiers in pharmacology. 2018;9(1348). 
71. EMBU. Embu Level 5 Referral Hospital - Embu County. 2021. Available at URL: https://www.embuhospital.go.ke/.

72. Guney Z. Insulin and its analogues - what are they for? (pros and cons). Trends in Diabetes and Metabolism. 2019; 2 (1-2).

73. Moon JC, Godman B, Petzold M, Alvarez-Madrazo S, Bennett K, Bishop I. Different initiatives across Europe to enhance losartan utilization post generics: impact and implications. Frontiers in pharmacology. 2014;5:219.

74. Godman B, Petzold M, Bennett K, Bennie M, Bucsics A, Finlayson AE. Can authorities appreciably enhance the prescribing of oral generic risperidone to conserve resources? Findings from across Europe and their implications. BMC medicine. 2014;12:98.

75. Godman B, Hill A, Simoens S, Kurdi A, Gulbinovič J, Martin AP. Pricing of oral generic cancer medicines in 25 European countries; findings and implications. Generics and Biosimilars Initiative Journal (GaBI Journal). 2019;8(2):49-70.

76. Leporowski A, Godman B, Kurdi A, MacBrideStewart S, Ryan M, Hurding S. Ongoing activities to optimize the quality and efficiency of lipid-lowering agents in the Scottish national health service: influence and implications. Expert review of pharmacoeconomics \& outcomes research. 2018;18(6):655-66.

77. Ball D, Ewen M, Laing R, Beran D. Insulin price components: case studies in six low/middle-income countries. BMJ global health. 2019;4(5):e001705.

78. Iqbal Q, Bashir S, Iqbal J, Iftikhar S, Godman B. Assessment of medication adherence among type 2 diabetic patients in Quetta city, Pakistan. Postgraduate medicine. 2017;129(6):637-43.

79. Waari G, Mutai J, Gikunju J. Medication adherence and factors associated with poor adherence among type 2 diabetes mellitus patients on follow-up at Kenyatta National Hospital, Kenya. Pan Afr Med J. 2018;29:82.

80. Moosa A, Bezuidenhout S, Meyer JC, Godman B. Knowledge regarding medicines management of type2 diabetes among patients attending a Community Health Centre in South Africa. Journal of Pharmaceutical Health Services Research. 2019, 10; $13-21$.
81. Department of Health Republic of South Africa. National Essential Medicines List Committee (NEMLC) - tertiary and quaternary level essential medicines list Reviewed Items. 2020. Available at URL:

http://www.kznhealth.gov.za/pharmacy/Tertiaryquaternary-level-essential-medicinerecommendations_January2020.pdf.

82. CONITEC. Relatório para sociedade. Insulina análoga de ação prolongada para o tratamento de diabetes mellitus tipo I. 2019. Available at URL: http://conitec.gov.br/images/Consultas/Relatorios/201 8/Sociedade/ReSoc136_INSULINAS_ANALOGAS_ diabetes_tipoI_FINAL.PDF.

83. Singh S. Biocon's Malaysia Insulin Glargine Manufacturing Facility Receives EU GMP Certification. 2019. Available at URL: https://indiamedtoday.com/biocons-malaysia-insulinglargine-manufacturing-facility-receives-eu-gmpcertification/.

84. Colloca L, Panaccione R, Murphy TK. The Clinical Implications of Nocebo Effects for Biosimilar Therapy. Frontiers in pharmacology. 2019;10(1372).

85. Hadjiyianni I, Dahl D, Lacaya LB, Pollom RK, Chang CL, Ilag LL. Efficacy and safety of LY2963016 insulin glargine in patients with type 1 and type 2 diabetes previously treated with insulin glargine. Diabetes, obesity \& metabolism. 2016;18(4):425-9.

86. Blevins TC, Barve A, Raiter Y, Aubonnet P, Athalye S, Sun B. Efficacy and safety of MYL-1501D versus insulin glargine in people with type 1 diabetes mellitus: Results of the INSTRIDE 3 phase 3 switch study. Diabetes, obesity \& metabolism. 2020;22(3):365-72.

87. Lamb YN, Syed YY. LY2963016 Insulin Glargine: A Review in Type 1 and 2 Diabetes. BioDrugs : clinical immunotherapeutics, biopharmaceuticals and gene therapy. 2018;32(1):91-8.

88. Mwita JC, Francis JM, Omech B, Botsile E, Oyewo A, Mokgwathi M. Glycaemic, blood pressure and low-density lipoprotein-cholesterol control among patients with diabetes mellitus in a specialised clinic in Botswana: a cross-sectional study. BMJ open. 2019;9(7):e026807. 